\title{
Teaching Research on Introduction to Cultural Heritage Under the Flipped Classroom Model
}

\author{
Shuyan Pei ${ }^{1, *}$ Yajie $\mathrm{Hu}^{1}$ \\ ${ }^{1}$ School of Historical Culture and Tourism, Xi'an University, Xi'an, Shaanxi 710065, China \\ *Corresponding author. Email: 867252771@qq.com
}

\begin{abstract}
Introduction to Cultural Heritage, as the core course of archaeology, and cultural relics and museology, is a compulsory course for the professional basis of talent training program. It mainly trains students to understand the cultural heritage left by human activities and study the complexity and diversity of human social values with professional knowledge and broad vision. Flipped classroom is a new teaching model that subverts traditional teaching. The initiative of learning is transferred from teachers to students. Taking Introduction to Cultural Heritage as an example, this paper tries to analyze the necessity and effectiveness of curriculum reform under the flipped classroom model.
\end{abstract}

\section{Keywords: flipped classroom, Introduction to Cultural Heritage, curriculum reform}

\section{INTRODUCTION}

Launched in the United States in 2007, flipped classroom has gradually become a hot topic in China's education sector since it was introduced in 2011. Schools and educational institutions at all levels have conducted different teaching research and teaching attempts. In 2018, the Ministry of Education issued Opinions on Accelerating the Construction of Highlevel Undergraduate Education and Improving the Ability of Talent Cultivation, stating that it is necessary to speed up the classroom teaching revolution, enhance the learning revolution through teaching reform, and actively promote small-class teaching, blend learning, and flipped classroom. Classroom teaching methods should be selected due to the curriculum. At the same time, it is proposed to strengthen the management of learning process and increase the proportion of process assessment score in the total score of the course. [1] Against such backdrop, the major of Cultural Heritage and Museology in the School of Historical Culture and Tourism of Xi'an University actively introduced flipped classroom model to reform the curriculum in order to improve the quality of teaching. This paper takes Introduction to Cultural Heritage, the core course of Cultural Heritage and Museology, as an example, trying to analyze the necessity, application, existing problems, and effectiveness of the model, and to provide new perspectives and insight for the teaching reform of other courses.

\section{TEACHING STATUS OF INTRODUCTION TO CULTURAL HERITAGE}

Introduction to Cultural Heritage is the core course of archaeology, cultural heritage and museology, preservation techniques of cultural relics, and other majors. It is also a professional foundation course in talent training program. It occupies a large proportion in the undergraduate teaching of archaeology, and cultural heritage and museology, and applies to the undergraduate teaching of history. This course is suitable for sophomore (first semester) in archaeology, and cultural heritage and museology, and junior (first semester) in history. Students studying the course are required to master basic theory, knowledge, and core skills of cultural heritage, grasp the basic methods and means of literature retrieval and information inquiry, enjoy good research and paper-writing skills, be capable of conducting comprehensive research on cultural relics, museology and archaeology with broad vision and independent thinking, and understand concerned humanities, social sciences, and natural sciences. The course covers a wide range of contents, including the basic meaning of cultural heritage, classification and evaluation, and protection and utilization of cultural heritage, as well as the basic knowledge of cultural heritage in the Paleolithic Age, Neolithic Age, Xia, Shang, Zhou, Spring and Autumn, Sui, Tang, Song, Yuan, Ming, Qing, and modern times. There are four parts to be taught. The first part is the theoretical method, namely the overview of cultural heritage and cultural heritage economics with the cognition of cultural heritage as its core. The second part is the protection and utilization of cultural heritage, that is, the protection and development of tangible 
cultural heritage, intangible cultural heritage, both cultural and natural heritages, and digitalized protection and utilization of cultural heritage. The third part is the resource theory of cultural heritage and the value theory of cultural heritage. The fourth part is the cultural heritage law and policy. It can be seen that this course requires students to master more and deeper professional knowledge, and has higher requirements for students' professional literacy. In addition, the previous teaching mode of this course is centered on the professional teachers of the school with external teachers are responsible for their specialized courses. Due to the three teachers' emphasis on the depth of the teaching contents, the connection in the teaching process is loose, resulting in inadequate course cohesion. In addition, the students attending the class are all freshmen, lacking solid professional foundation, resulting in a heavy classroom atmosphere. Some students who lack the ability to explore and study deeply have poor effect in class. Therefore, it is particularly important to employ the right teaching mode. The expectation that students can master a lot of theoretical knowledge, have the ability of independent thinking and research, and develop divergent thinking and professional insight on the basis of understanding the content of the textbook encourage the adoption of flipped classroom. In this mode, students take the initiative in learning and become the leading role in class, which can not only enable students to engage in "immersive" learning, improve professional identity, but also truly implement the new learning mode of "preparation after class, play in class".

The flipped teaching project of Introduction to Cultural Heritage was carried out on the basis of the flipped teaching project of Chinese Archaeology, a comprehensive teaching reform project of Xi'an University, with some changes. After three years of practice, the reform of the flipped teaching project of Chinese Archaeology has witnessed continuous improvement in classroom activity, students' cognition, and course evaluation, providing new ideas for teaching reform of other courses. The audience of Introduction to Cultural Heritage has changed from freshman (second semester) majoring in cultural heritage and museology to sophomore (first semester) in the major, with an annual teaching number of 40 students. The course category has been upgraded from basic courses to core courses, and the class time has been increased from 48 hours to 64 hours, and on-site teaching has been added. Through the reform of flipped teaching, the teaching of Introduction to Cultural Heritage has achieved good results. Students' recognition and professional identity are high, and examination and examination results also show that students have mastered the basic knowledge and theory of cultural heritage.

\section{OVERVIEW OF THE FLIPPED CLASSROOM TEACHING MODEL}

The Opinions on Further Strengthening Undergraduate Teaching in Colleges and Universities issued by Ministry of Education proposes "to continue to promote the reform of the curriculum system, teaching content, teaching methods, and build a new curriculum structure. It is necessary to effectively change the situation that classroom lectures occupy too many weekly teaching hours, and provide students with more time and space for self-learning." "It's a must to actively promote research-based teaching, improve the innovative ability of college students, enhance discussion teaching, case teaching and other teaching methods and cooperative learning methods, encourage college students to understand a variety of academic views, carry out discussions, track the latest progress in the discipline, and improve the ability of independent learning and research." [2] In this context, flipped classroom model is gradually prevailing in China's education sector.

Flipped classroom is a new teaching model that subverts traditional teaching. The initiative of learning is transferred from the teacher to students, and students take the lead in the class. Instead of emphasizing on acceptive learning, rote learning and mechanical training, students are encouraged to participate actively, explore, and think diligently. Flipped classroom in the traditional sense refers to the replacement of face-toface teaching with video after class, allowing students to conduct self-study, so that students can have more spare time in class to participate in key learning activities with teacher. However, with the continuous improvement of teaching methods and the collision of different educational ideas, flipped classroom is no longer limited to after-class video lectures, but emphasizes the independent learning environment of students and the interaction and communication between teachers and students, so that every student can participate in the teaching process and get personalized education. Under this teaching mode, students actively collect basic course materials before class, which greatly shortens teachers' explanation time. Valuable class time can be used for discussion, experiment, and result display, so that students can grasp the class and master knowledge more efficiently through practice.

The application of the flipped classroom in Introduction to Cultural Heritage has transformed "after-class video-watching learning" into "student selfsponsored teaching", which solves the limitations of the course. The curriculum reform is mainly based on the following aspects: First, the mode of "teachers' division of labor" has not achieved ideal effect. The teachers value depth of profession over the generality of "introduction" and the acceptance degree of students. The second is to change "full lecture" and "spoon- 
feeding" teaching, promote interactive, heuristic, discussion teaching to promote the continuous improvement of learning style. The third is to solve the problem of students not attending lectures, lowing heads, skipping class, playing mobile phones, to cultivate a good learning style. The fourth is to tackle the problem of focusing on knowledge transfer over ability training, and to cultivate students' independence. Passive learning in middle school has restrained students' independent thinking and divergent thinking, while flipped classroom provides students with the opportunity to learn independently before class and explain independently in class, which not only exercises students, but also releases their creativity and personality. Fifth, flipped classroom model can greatly improve learning efficiency. As planned by teachers, students can study independently before class according to requirements and progress, and bring the doubts encountered in self-study into the class, so as to achieve purposeful and focused learning, without wasting valuable class time. The sixth is to respect students' status as learning subjects. Students are the subject of learning. Allowing students time to show and discuss their achievements in class is conducive to improving students' participation and initiative, thus stimulating their professional identity and learning enthusiasm.

\section{APPLICATION OF THE FLIPPED CLASSROOM IN INTRODUCTION TO CULTURAL HERITAGE}

Introduction to Cultural Heritage has a total of 64 lessons, 4 lessons per week, and will be completed in 16 weeks. The class schedule is divided into five parts. The first part is the curriculum framework and core communication, which consists of 8 periods. The second part is topic preparation and flipped classroom, which is 16 hours in total. The third part is problem setting and group discussion, with a total of 16 periods. The fourth part is about interest promotion and case explanations, with a total of 16 hours. The fifth part is about professional cognition and career planning. Based on the development and improvement of archaeology, and cultural heritage and museology in recent years, it tells the current situation and prospect of the two, and informs students of the important trends of the two industries and academia inside and outside China. This part has 8 periods.

\section{A. Curriculum framework and core communication}

This part is led by teachers, who, as a guide to students' learning, play an important guiding role in students' learning. Especially at the beginning of a new course, the effect of teachers' guiding will have a direct impact on students' later learning. In addition, Introduction to Cultural Heritage, as the core course of cultural heritage and museology, covers the core knowledge, basic theories, and research methods of the major. Therefore, teachers should guide students to establish the overall cognition and learning objectives of the discipline system. Therefore, in the first 8 hours (first two weeks), the teacher must seize the opportunity to explain the coverage of cultural heritage and the design objects with their own detailed knowledge and broad academic horizons, so that the students can lay a solid foundation in the early stage of learning, generate a strong interest in learning, pave the way for independent and in-depth study afterwards.

\section{B. Topic preparation and flipped classroom}

This part takes students as the main body and is arranged by teachers. Teachers arrange students to choose topics and make groups according to the overall plan of the course, highlighting the core issues involved in the course and teaching materials, as well as the teaching forms and methods of students' topic selection. The topic selection follows the voluntary principle. Students choose the topic independently and divide into 6 groups according to the topic scope. As for grouping, the students who got A+ in the teaching session of Chinese Archaeology last semester will be the driving members of this course, and they will be assigned to each group as the leader, who will be responsible for the coordination and cooperation within the group and the order of the group members' lectures. In addition, students are required to spend two weeks preparing the assigned course content and submit a PPT of the lecture as the first assignment, accounting for $10 \%$ of the total grade.

From the third week, students are required to independently make lecture in odd weeks, and one person from each group will be sent every week. Students should finish the lecture within 15-18 minutes. The lecture should be of macro generality, clear goal, correct content, clear complexity, prominent key and difficult points, clear organization, and proper language, which can attract other students into learning state and master the knowledge. After students finish teaching, teachers shall review and summarize, and the time shall be controlled within 7-10 minutes. The key and difficult points of this section shall be clarified. During the break, the teacher may give the student a score for the teaching part according to the rating sheet submitted by the review group, and the score shall be counted as $20 \%$ of the usual score.

\section{Problem setting and group discussion}

This part takes students as the main body, and each group leader as the member of the statistics and evaluation working group in the discussion session. From the fourth week, the bi-weekly group discussion session is introduced. Each group raised a core question about the teaching contents of the other five teaching groups in the previous week and summarized it to the 
teacher. The teacher selects one question from the five questions in each group, and each group conducts class discussion on this issue, and sends a representative to share the discussion results. Finally, the teacher summarizes. After the discussion, the teacher picks one of the core questions of this course as the course assignment, and requires the students to extend or go deeper on the basis of the conclusions they have reached, and submit it before the next discussion course as second assignment, each of which accounts for $5 \%$ of the total score. There are six assignments in this section.

This part requires the non-teaching group to be careful and meticulous in listening, prepare questions, and raise specific and realistic questions. The teaching group is required to have a firm grasp of the content, expand appropriately, focus on the parts that may have doubts, and actively discuss with the team members before class to help each other and solve problems. Teachers are required to enlightening and inducing students' questions that cannot be answered in a timely manner, and to further answer them, and then to summarize and systematize students' knowledge.

\section{Interest promotion and case explanation}

This part occupies 16 lessons and is divided into two courses. Through field teaching, students are organized to conduct field visits and researches, so as to acquire or consolidate knowledge in practice. Students can be organized to visit movable cultural heritage (museums) and immovable cultural heritage (archaeological sites, cultural sites) in Xi'an, and employ physical objects and immersion environment to enhance students' professional cognition and learning interest. Teachers are required to prepare for the visit or inspection in advance, give specific guidance to students during the visit, and timely urge students to complete the on-site teaching report after the visit, and summarize the problems. This part highlights students' research learning ability and report and paper writing ability, while dilutes the dominant position of teachers, and turns teachers into assistants. The onsite teaching report of this link is included in the total score, accounting for $10 \%$ of the total score.

\section{E. Professional cognition}

This session was conducted in the last 8 periods, with the aim of enabling students to establish a systematic discipline system and develop a sense of identity for their major through preliminary basic learning, independent teaching, group questioning and on-site teaching. On this basis, teachers will describe the professional prospect in combination with the dynamic development of the archaeology, cultural heritage and museology, and the academic circle in recent years, so as to establish students' self-confidence and preliminary professional career planning, which is very important for students' future study or employment. This part can be called the "sublimation" part of the teaching of Introduction to Cultural Heritage. Teachers are required to guide students to love cultural relics and museology, and archaeology, and to become professionals with profound humanistic quality, rigorous scientific spirit, awareness of the times, and international vision.

\section{F. Assessment method}

Flipped classroom pays more attention to performance of students in learning process. Therefore, it attaches importance to students' learning results in the process over final closed-book exam. "The method of comprehensive assessment was adopted, under which the usual score and final score were comprehensively considered, and the assessment proportion of the usual score was increased." [3] The regular score accounts for $70 \%$ of the total score, and the final exam accounts for $30 \%$. The final exam will last for one hour and will be based on the comprehensive application of the course (subjective questions). The usual grades cover attendance, teaching sessions, discussion, assignments, and inspection reports. Attendance accounts for $10 \%$ of the total score, and each of the 6 assignments accounts for $5 \%$, accounting for $30 \%$. (The result of homework is divided into excellent, good, and qualified, and excellent is 5 points, good is 4 points, while qualified 3 points.) The lectures will account for $20 \%$ of the total grade, and the report $10 \%$. Such method has not only realized the transformation from results-oriented evaluation to process-oriented evaluation, but also paid more attention to the comprehensive evaluation of students from various aspects.

For a long time, people have been studying teaching methods, teaching content, which has led to educational reforms that have changed with the times. The core of education reform is curriculum reform. Flipped classroom, as a new type of curriculum, has injected fresh vitality into the reform of undergraduate teaching in colleges and universities. It integrates independent learning, cooperative learning, and research-based learning, changes the situation that teachers occupy too much weekly teaching hours, provides students with more time and space for independent learning, cultivates students' teamwork ability and sense of responsibility, and improves students' independent research ability and academic interest. The adoption of the flipped classroom model in the teaching of Introduction to Cultural Heritage is an active choice against the background of the new curriculum reform.

\section{PROBLEMS IN EDUCATIONAL REFORM AND COUNTERMEASURES}

The problems in the course focus on the links of "students' teaching" and "group questions". As students 
are accustomed to the traditional classroom teaching mode in middle school, they have poor independent learning ability in the flipped classroom, which leads to imperfect early preparation and incomplete teaching content, affecting the teaching effect. In addition, in the traditional class, the teacher is the main body, and students rarely have the opportunity to stand on the platform to teach independently. Therefore, most of them are afraid and nervous, resulting in low voice, stiff language, lack of interaction, and teaching time postponement, which are not conducive to students' real performance, creating unfavorable classroom atmosphere. As for group questioning, students do not listen carefully, and raise repetitive and meaningless questions, and students' own ability is varied.

The problems existing in the above teaching links can be improved by strengthening the work in the preclass preparation stage. Before class, the cooperation within the group should be strengthened. The group leader should urge the team members to prepare lessons carefully, and organize several trial lectures within the group, put forward suggestions for improvement in time. In addition, courage should be exercised in many exercises to overcome nervousness. Problems existing in the group questioning session can be improved by establishing long-term evaluation and incentive mechanism. Students who do not listen carefully and ask repeated questions or simple questions will be penalized in this section. In addition, teachers should guide students and strengthen communication with students.

\section{THE EFFECT OF EDUCATIONAL REFORM}

The time inside and outside the classroom is adjusted, and the decision and initiative of learning are given to students, which can train students to establish knowledge system independently. At the same time, the process of students' self-preparation is also the process of looking up materials, sorting out, compiling, and organizing languages, which is a good way to broaden students' knowledge and stimulate their academic interest. Students' experience of lecturing is also a process of internalizing knowledge and deepening understanding. It is also an exercise to break through and show oneself. The introduction of the flipped classroom model in the teaching process of Introduction to Cultural Heritage enables students to independently plan the learning content, rhythm, style, and outcome presentation, making the theoretical learning content more flexible and vivid. In addition, it also enhances the interaction between teachers and students. Teachers have more opportunities to communicate with students, so that they can directly understand students' weak points of knowledge and teaching priorities, and timely improve teaching methods based on students' feedback, so as to achieve a "win-win" situation. Therefore, the reform of this course not only improves the comprehensive quality of students, promotes the innovation and perfection of teachers' teaching ideas and methods, but also enhances professional development.

The major of Cultural Heritage and Museology in Xi'an University is currently under construction and improvement. In terms of the composition of students, all of them are undergraduates. In the past three years, the first-choice rate of students enrolled has increased from $8 \%$ to $38 \%$. Although the number of students who love their major increases year by year, their knowledge and understanding of their major are still insufficient. [5] The application of flipped classroom to Introduction to Cultural Heritage has enabled students to learn professional knowledge, develop the ability to collect and process data, to think independently, to acquire new knowledge, to analyze and solve problems, and to communicate and cooperate. What's more, it has trained students' courage and improved their professional cognition and identity. Thanks to the five-in-one flipped classroom covering "teacher guidance", "student lecturing", "group questions", "on-site teaching", and "professional cognition", Students have identified the talent training objectives of their major, raised their interest and enthusiasm in professional learning, enhanced their confidence and pride, clarified their future research and employment direction, and enhanced their love for and identification with cultural heritage and museology, and archaeological industries. This will inject a positive force into the development of the two industries and gradually promote the social recognition.

\section{CONCLUSION}

Quality is the lifeline of higher education, and improving the quality of higher education is the only way to accelerate the modernization of education. [6] Classroom, which directly connects teachers and students, is the main position of teaching reform and a barometer of teaching quality. Therefore, promoting teaching quality through curriculum reform is particularly important in education and teaching. The curriculum reform of Introduction to Cultural Heritage proves that flipped classroom has greatly stimulated students' learning enthusiasm and teachers' teaching quality, whose value lies not only in students' personal development, but also in providing a new model for educational reform and improving teaching quality. However, there are also many problems in the actual teaching process, which need further rectification and improvement.

Given higher education's increasingly emphasis on students' all-round development and comprehensive quality, flipped classroom has satisfied such requirement with flexibility and practicality, and is gradually prevailing in China's education sect. It is 
worth noting that different subjects should be adjusted in terms of teaching content, period setting, and teaching methods according to the characteristics of the subjects. At the same time, the intensity of reform and the degree of acceptance of students should also be considered, so as to make the flipped classroom contribute more to the modernization of higher education in China.

\section{References}

[1] Ministry of Education of the People's Republic of China. Opinions on Accelerating the Construction of High-level Undergraduate Education and Improving the Ability of Talent Cultivation [N]. State Council Bulletin of the People's Republic of China, 2019-3: 36-37. (in Chinese)

[2] Ministry of Education of the People's Republic of China. Opinions on Further Strengthening Undergraduate Teaching in Colleges and Universities [J]. China University Teaching. 2005 (2): 4-5. (in Chinese)

[3] Guo Yong'ai. The Application of Flipped Classroom Teaching Mode in the Course of Ideological and Moral Cultivation and the Basics of Law in Colleges and Universities [J]. Education (Higher Education Forum). 2018 (36): 85. (in Chinese)

[4] Li Hailong. Understanding Teaching Reform from the Perspective of Knowledge Innovation [N]. Journal of Yangzhou University (Higher Education Study Edition). 2018 (6): 30. (in Chinese)

[5] Pei Shuyan. Exploration and Practice of the Teaching Reform of the Course of "Archaeology" [J]. Education and Teaching Forum. 2020 (2). (in Chinese)

[6] Gong Jinlong. Leading the construction of a strong country with higher education $[\mathrm{N}]$. Learning Times, 2019-8-9 (6). (in Chinese) 